\title{
A Comparative Study on the Construction of Oriental Female Music Images in Chinese and Western Opera—_ Take Madame Butterfly and Canal Ballads as examples
}

\author{
Beibei Li \\ Institute of Technology, East China Jiao Tong University, Nanchang, Jiangxi, China
}

Keywords: Female music image; Madame butterfly; Canal ballad

\begin{abstract}
The national opera Canal Ballad tells a touching love story with the Beijing-Hangzhou Grand Canal created by the working people in ancient China as the background. Puccini's opera Madame Butterfly describes a humiliated oriental woman who fell in love with a fickle western man without complaint or regret, waited for him faithfully for three years, and finally was ruthlessly abandoned and committed suicide in despair. Through the basic music materials expressed in the operas Madame Butterfly and Canal Ballad, this paper has a preliminary understanding of the author's creative ideas. With women as the leading role, strong exotic sentiment, strong love, perfect combination of drama and lyricism, this paper compares and analyzes the use of oriental elements in these two works from the perspective of music, and discusses the unique charm of opera.
\end{abstract}

\section{Introduction}

Puccini is another outstanding and highly respected opera composer after Verdi. His opera art is deeply rooted in Italian traditional culture. He is the inheritor and promoter of Verdi's musical style, with excellent theater instinct and considerable melody talent, and the characterization of female characters is very typical [1]. Puccini likes to directly absorb the local folk songs, and use the music with local colors to express the characters or render the atmosphere, which makes the opera exotic.

The creation of Chinese opera is more and more liberated from the shackles of the past, and all kinds of music styles have their own development space, and learn from each other's strong points. In vocal music. We can use Bel Canto skills more to serve the shaping of music image. Canal Ballad is an original national opera written by Huang Weiruo and Dong Ni, a famous contemporary playwright and professor of the Central Academy of Drama, composed by Yin Qing and directed by Liao Xianghong. Since its premiere at the National Centre for the Performing Arts in 2012, it has aroused strong response from the audience and high praise from the industry [3]. Excavating the oriental music elements in the classic operas Madame Butterfly and Canal Ballads and their application of "exotic sentiment" can help us understand the oriental music written by Westerners, feel the charm of oriental music and its oriental female image, and further understand the oriental female image endowed by oriental music.

\section{Penetration of Oriental Elements in Puccini's Opera Creation}

Oriental women in Puccini's works are extremely dedicated. In the corner of Liuer in Turandot, he made great changes in the image description compared with the earlier Turandot version. It is a subversive originality. Opera tells the story of a Turandot who, as a Chinese princess, avenged her ancestors' capture by night, and ordered a man to marry him if he could guess his three riddles. If you guess wrong, you will be put to death. Westerners show their masculine side by dominating and abusing the feelings of oriental women. Western masculinity is closely related to the domination of oriental women. This rule is not only gender but also political. Qiaoqiao sang in Madame Butterfly looks slim and shy. She didn't have many principles of being a man, gave up her faith and followed Pinkerton to believe in Christ. Even though the servant repeatedly advised her that Pinkerton had abandoned her. However, Butterfly is stubborn and misses the pursuit of Japanese businessmen. The 
national mode is mixed with the western major and minor systems, and the harmony function is not very clear, but its whole image has created a cold and beautiful Oriental princess.

Qiaoqiao sang is a gentle and lovely woman with a strong heart. Her character includes passion for love and silence in the face of setbacks. There are traditional Japanese women's obedience, but also desperate resistance in pursuit of love, which shows the heroine's ridicule for those princes who came to courtship and fell by the sword. The melody gradually reached its climax. The voice here is full of farcicality, emphasizing her disdain for those people and her complacency. As you can imagine, the result of waiting for many years is that Qiaoqiao sang's heart must be full of despair, but she hides this grief and despair in her heart. To some extent, some traditional parts have been swept into the garbage dump of history. Because of cultural origin, Chinese women and Japanese women have more similarities. Even Qiaoqiao sang has been yearning for true love and firmly believing in their vows for several years, but he was finally abandoned by Pinkerton relentlessly. What is even more frightening is that Qiaoqiao sang acquiesced in this unequal relationship and willingly went to death.

\section{Appreciation of Opera Madame Butterfly}

Opera Madame Butterfly is another oriental work by Puccini. Opera tells the story of Qiaoqiao sang (Butterfly Girl), an innocent, lively and pure Japanese girl, who abandons traditional new beliefs for love. Married to an American navy captain Pinkerton, and eventually abandoned by him. Finally, commit suicide to end his romantic and tragic life. This is a lyrical tragedy.

Qiaoqiao sang in Madame Butterfly looks slim and shy. She didn't have many principles of being a man, gave up her faith and followed Pinkerton to believe in Christ. Even though the servant repeatedly advised her that Pinkerton had abandoned her. In the musical depiction of Qiaoqiao sang's character, Puccini compared and combined the very different eastern and western worlds, rendered the oriental sentiment, used real Japanese tunes and pentatonic scales, and conceived new melodies and rhythms on the basis of folk songs, which made it more exotic. When Qiaoqiao sang and her friends appeared on the stage, the charming tune expressed the characteristics of this elegant and beautiful girl: love is her life, her love is delicate and unpredictable, but she can sacrifice herself for her lover.

The rhythmic characteristics of music melody also restrict the vocalization of singing [4]. How to complete the trend of musical form and melody. Rhythm, length, strength and voice of music are the comprehensive embodiment of singing skills and singing ability of opera singers. When the consul and other officials made the contract right, and all the guests were happy, the theme of love appeared beautifully and enthusiastically as Pinkel went to Qiaoqiao Sang. It is the foundation of the whole music image.It is commendable that the composer not only successfully created such a perfect theme of music in the style of chanting, but also made good use of the melody in the style of recitation to compare with it, and then depicted the details of the inner activities of the characters. Using different music to represent different characters and different emotions, skillfully combining the melodies of oriental Japanese ancient ballads and musical elements of pentatonic order makes the works full of exotic charm.

In Madame Butterfly, the use of eastern and western music is also very clear. There is a sharp contrast between the prominence of Japanese style theme and the musical depiction of western characters in opera. In the opera, it shows Qiaoqiao sang's identity as a Japanese geisha and his innocent state of mind. Japanese folk songs "Edo Japan Bridge", "Lion Dance" and "Cherry Blossom" are used to depict. And pay attention to the use of Japanese pop melody features to describe the exotic style, and make it organically combined with Italian style. Puccini studied Japanese folk music in detail in order to reflect the exoticism of his works. It is said that he has listened to hundreds of records. Music is mainly written by contrasting aria with recitation. First, it is a beautiful aria, and then it is a recitation of a recitative lyric melody. This broad, beautiful and beautiful aria melody intersects with expressive recitative voice, forming a unique style of Puccini opera. 
The heroine in Canal Ballad is neither a woman bullied and oppressed by feudal forces, nor a revolutionary heroine who kills enemies on the battlefield, but a singer who travels across the country, that is, a geisha in ancient times. Aesthetic concepts and tastes directly affect the actor's orientation of vocal value, how to make sound correct and beautiful, and how to adjust and optimize timbre and resonance, etc. Shui Honglian is portrayed as a Jianghu artist who dares to love and hate and has a sense of justice. She is strong-willed, witty, pungent and kind. For the sake of love, justice and the pursuit of great love in the world, she finally died. Her death not only reflects a kind of love for Guan Yanyan and Qin Xiaosheng; However, in the end, the fierce and witty chivalrous woman set fire to the bully Zhang Shuiyao's boat in order to escape from Guan Yanyan and Qin Xiaosheng, and she also died in the sea of fire, showing her great human love of sacrificing her life for righteousness and self-being [5].

The development and promotion of the storyline in opera is carried and revealed by characters [6]. Shui Honglian in Canal Ballad is a kind-hearted, intelligent, positive and optimistic, vigorous and playful, with clear love and hate, and a "female man" who dares to love and hate. In the 42nd section, the whole song turned to the close relation $\mathrm{G}$ feather mode, and the last three times, which pushed the mood of the whole song to a climax, and showed the eagerness of Guan Yan Yan to save Qin Sheng. Finally, we use Honglian's call to Qin Sheng to make the final recovery, which not only sublimates the regret of losing Honglian in Guan Yan's heart, but also pays homage to Honglian's sacrifice by saving Qin Sheng's life. When she knew about the blind girl Guan Yanyan, her heart was very tangled. She said to Qin Xiaosheng, "Maybe this is our sorrow." Yes, this is their sorrow. Clearly, it is two lovers who love each other, but they are so close at hand. When a happy life is being recruited from them, such a thing happened. When singing the latter part, the emotion and breath should be fuller, the breath should flow actively, the confrontation between waist and abdomen should be strengthened, and the great lines of breath should be used to tell the historical vicissitudes of the canal.

In the first act of the opera, Qiaoqiao sang rushed to the wedding scene, and consul Shapus asked if butterfly was a bench man. Madame Butterfly answered yes, and then began to tell her family history. Butterfly said: No one is willing to admit that they were born in poverty, and not everyone's ancestors were homeless. But I was once rich. With the continuous development of the plot, the characters of Shui Honglian are getting fuller and fuller, and the music representing Shui Honglian is constantly changing. First, from the folk song Canal Ballad at the beginning to the aria Love You in the Afterlife, we can see that the opera music is getting more and more tense, spiraling up together with the plot, pushing the whole drama to a climax. At the coming moment of death, Qin Sheng still has a lot to give up in his heart. When you sing, you should experience the sad situation of Honglian's great love and selflessness, and bring tears with gentle and coherent breath. In terms of rhythm and beat, triplets are used many times in accompaniment and melody, which is more frequently used than the previous two paragraphs, which is to show the inner anxiety and tension of Guan inkstone.

\section{The Comparison of Musical Images between Opera Madame Butterfly and Canal Ballad}

It is not difficult to find that almost all the Japanese themes in the opera Madame Butterfly appear with the heroine, and other paragraphs also appear with several other Japanese people in the play. Although Puccini wants to use these Japanese-style music materials to set off the identity and fate of the characters, it can be said that Puccini's adoption of Japanese-style tunes as opera background music is very successful. And absorbed the melody of Chinese folk songs as the material, and processed and refined the melody with the most Chinese characteristics, which made Madame Butterfly have a unique Chinese temperament. The creation of "Canal Ballad" is positioned as a national opera, which does not only pay attention to music but not to the storyline. With the Beijing-Hangzhou Grand Canal as the story background, the characters are positioned as ordinary people living on both sides of the canal. Although they describe the stories between these little people, they embody the national spirit of the Chinese people. Melody and structure are relatively short, without more ups and downs, and the style is simple, but these simple melodies give wings to our thoughts, so that we can follow this beautiful lyric melody and see the beautiful and rich canal. 
Everyone who has seen the opera "Canal Ballad" must be impressed by the beautiful melody "We are the Water of the Canal", and even can hum the melody after watching it once. As far as Puccini's oriental female music image is concerned, the mystery, beauty, closeness of Princess Turandot and the romantic warmth of Qiaoqiao sang may be the author's inner perception of the oriental female's cognitive level represented by Chinese and Japanese culture. Yin Qing, the famous composer of Canal Ballad, created a kind, beautiful and pleasant melody for the play, which integrated the melodious folk songs with the tension of opera. However, Puccini's characterization of the characters in Madame Butterfly has spent a lot of money, and the unique charm of the whole opera is further highlighted by setting off the characters with exotic melodies. Especially, "he will call the little butterfly one after another", the music slows down and enters the bass area, which makes people feel that Madame Butterfly is whispering, full of fantasy, and it is simply infatuation.

Chinese traditional culture is a culture with spiritual experience as its core. It is the most important way of thinking of Chinese ancient people and the ancient people's attitude of contemplating the universe and life [7]. It is necessary to sing because of drama and love. So what is the emotion expressed in the aria "Love You in the Afterlife"? The author thinks it is the dialectical view and values of life and death, emotion and reason, giving up and gaining. The disintegration and destruction of individuals is the greatest pain, but this pain has become the root of relieving all pain. Tragedy shows people the pain and destruction of individuals, but it gives people pleasure and makes people feel the indestructible will of life from illusion. Compared with Qiaoqiao sang's infatuation and loyalty, Pinkerton's playing with oriental women's feelings and life is also vividly reflected in his music. In order to make the strong exotic sentiment directly used in chord melody lines, Puccini also created some folk tunes similar to the East under bold imagination. On the other hand, the mysterious ascending fourth grade tone is frequently used in harmony structure, aiming at depicting the feeling of oriental women that they are in bud, want to talk but are ashamed.

On the stage of opera, it is divided into descriptions of characters and props to show the skill of using oriental elements. Qiaoqiao sang's musical image has typical Japanese characteristics, and the use of Japanese folk songs such as Cherry Blossom and Edo Japanese Bridge in the middle has formed a strong oriental musical color. Puccini not only likes to choose weak female images, but also prefers the thoughts, feelings, joys and sorrows of the little people living at the bottom of society. Canal Ballad directly expresses the theme of opera, which is created around the canal, short and pithy, and enjoys both elegance and vulgarity. The song is soothing, smooth, fresh and refined. It is a folk song created by Yin Qing for the historic Thousand Miles Canal. It is the theme song of Canal Ballad, which is sung by the heroine Shui Honglian, in sharp contrast with other dramatic aria in the play. The melody of the ballad "Canal Ballad" is beautiful and beautiful, showing the gentle and sweet side of Shuihonglian's character. The aria "Love You in the Afterlife" is full of music. It uses the theater style of board cavity, and the tension of singing drama is extremely strong, which reflects the character character of Shui Honglian who dares to love and hate and is firm and resolute.

\section{Summary}

Puccini's oriental work Madame Butterfly has flourished in the West and even the whole world for a hundred years with the help of the magic of music and the unique artistic plot of the East. The feeling brought to us by Canal Ballad is also different from others. Perhaps only when you really walk into the theater will you have your own objective evaluation of this opera. It is of great significance to re-examine the interpretation of the East in the Italian opera Madame Butterfly. We hope that through historical investigation, we can eliminate cultural barriers. We can feel the oriental female images created by Westerners through music, and realize the unique oriental music features in Puccini's operas. This paper only has a basic understanding of the oriental female music images in the two operas, which still needs further exploration and deep thinking in the future.

\section{Acknowledgments}


Source of the project: The Humanities and Social Sciences 2019 Youth Project in Jiangxi Province Universities

Project Title: A Comparative Study on the Construction of Oriental Female Music Images in Chinese and Western Operas___ Taking "Madame Butterfly" and "Canal Ballad" as examples

Subject Number: YS19210

\section{References}

[1] Dou xuerui. study on the classic aria in contemporary Chinese national opera-taking the opera "osmanthus flowers bloom everywhere in August" and "canal ballad" as an example [J]. peony, (2019) No. 2Z, p. 75-77.

[2] Song Xiaoting. Exploring the artistic charm of the opera Madame Butterfly [J]. Drama House, Vol. 000 (2017) No. 009, p. 62-62.

[3] Xiu Xueqing. Study on the Singing of Chinese Contemporary Opera Works and Exploration on the Localization of Bel Canto Singing [J]. Northern Music, (2017) No. 37, p. 6-6.

[4] Li Yuting. A probe into the classical aria of the national opera "Canal Ballad"-with "Qin Sheng, are you all right? "For example [J]. Art Education, (2017) No. 5, p. 84-85.

[5] Zheng Qian. Study on the theme of opera "Canal Ballad" [J]. Contemporary Music, (2017) No. 12, p. 54-55.

[6] Dong Xiao. Talking about the opera "Canal Ballad" in the aria "Canal Ballad" and "The Eyes of Stars" [J]. Drama House, Vol. 000 (2018) No. 004, p. 56.

[7] Chen Xue. The national opera "Canal Ballad" Guan Yan's Character Creation [J]. Contemporary Music, Vol. 000 (2019,) No. 004, p. 29-32. 